\title{
Investigating causal factors of road damage: a case study
}

\author{
Jati Utomo Dwi Hatmoko*, Bagus Hario Setiadji, and Mohammad Agung Wibowo \\ Department of Civil Engineering, Diponegoro University, Jl. Prof. Soedarto, SH., Tembalang, Semarang 20775, Indonesia
}

\begin{abstract}
High rainfall leads to flood vulnerability and potentially leads to the failure of road pavement which affects the economic loss for the people. However, such road pavement failures need to be studied more deeply to be able to distinguish whether the failure is solely due to flood natural disaster or other factors, such as overloading and poor construction quality. This research is urgently needed because up to now there is no tool for assessing pavement failure as a tool of decision-making system that is able to distinguish road pavement failure causal factors into category of natural disaster or human negligence factors in accordance with the definition of building failure in Indonesia Law no. 2 year 2017. Assessment of the causal factor of failure is very important because it is closely related to the determination of the parties who must be legally responsible. This research intends to develop methods for assessing the damage and failure of pavement as a tool of rapid and accurate decision-making system to determine the factors of pavement failure. To obtain accurate results, a case study was taken on Kendal Timur road to enable a deep evaluation of the factors that causing failure on the road. The results showed that many factors involved in causing the failure of the road, such as un-functional drainage channel, uncontrolled overload due to the closing of weigh stations around the road, and also low quality of road maintenance work so that repeating similar road damages occurred in the not-too-distant future. Based on functional and structural failure analysis, as much as $71 \%, 10 \%$ and $19 \%$ of the road were in failed, critical and not-failed conditions, respectively.
\end{abstract}

\section{Introduction}

A pavement structure is generally designed to meet its service life, by taking into consideration the quality of materials used, environmental factors such as the amount of rainfall that will occur and the ability of the pavement (in this case the drainage channel) to reduce/eliminate the threat of environmental factors, and the magnitude of the predicted load will occur. However, at the time the pavement performs its function in serving the traffic, there is damage to the pavement structure which is often beyond prediction, especially in terms of the magnitude of environmental and load factors. This pavement damage could lead to the failure of road pavement which affects the economic loss for the people.

The process of identifying the causes of pavement failure and the severity level of damage occurred is usually carried out by the agencies and then several maintenance/rehabilitation plans are proposed. However, the proposed plans are generally only normative so it often does not touch the root cause of the pavement damage.

Therefore, in this study, the deterioration or even failure of pavement structures occurred needs to be further investigated to be able to distinguish whether the failure is caused only by natural disaster (such as floods) or due to other causes, such as overloading and lack of construction quality. Based on this, this research becomes very important to do because at present there is no tool that can be used to evaluate the failure of pavement and decide whether the failure of pavement structure is caused by natural disaster or human negligence factors as in accordance with the definition of building failure in Indonesia Law no. 2 year 2017. Assessment of the causal factor of failure is very important because it is closely related to the determination of the parties who must be legally responsible. This research intends to develop methods for assessing the damage and failure of pavement as a tool of rapid and accurate decision-making system to determine the factors of pavement failure.

\section{Causal factors}

There are 3 factors that will be reviewed in this research, i.e. excessive load factor, environmental factor (i.e. flood and sufficiency of drainage channel), and road construction quality.

* Corresponding author: jati.hatmoko@ft.undip.ac.id 


\subsection{Overload}

Excess load or overload has a significant impact on the achievement of the design life of the road. Overload leads to damaged roads prematurely and this will result in economic losses. Traffic load deviations occur when heavy vehicles carry loads beyond the allowable carrying capacity. An overloaded vehicle can cause its axle load in terms of ESAL (equivalent standard axle load) increase rapidly following the equation below.

$E S A L=k\left(\frac{\text { axle load }}{\text { standard axle load }}\right)^{4}$

in which: $k=$ a constant that depends on the number of axle (i.e. single, double or triple), standard axle load $=$ 8.16 ton.

The higher the number of repetitions of vehicles with excessive load, the lower the performance of road pavement, as indicated by the reduction of service life, will be.

\subsection{Environmental factor}

Environmental factor, water in this case, contributes significantly to pavement conditions [1]. In pavement structure design, water has been considered in terms of drainage coefficient, which is a function of drainage system quality and saturation condition of pavement structure within a year (see Table 1).

Table 1. Drainage coefficient for flexible pavement with untreated base and subbase materials [2]

\begin{tabular}{|l|c|c|c|c|}
\hline \multirow{2}{*}{$\begin{array}{c}\text { Quality } \\
\text { of }\end{array}$} & \multicolumn{4}{|c|}{$\begin{array}{c}\text { Percent of time pavement structure is exposed } \\
\text { to moisture levels approaching saturation }\end{array}$} \\
\cline { 2 - 5 } Drainage & $<1 \%$ & $1-5 \%$ & $5-25 \%$ & $>25 \%$ \\
\hline Excellent & $1.40-1.35$ & $1.35-1.30$ & $1.30-1.20$ & 1.20 \\
\hline Good & $1.35-1.25$ & $1.25-1.15$ & $1.15-1.00$ & 1.00 \\
\hline Fair & $1.25-1.15$ & $1.15-1.05$ & $1.00-0.80$ & 0.80 \\
\hline Poor & $1.15-1.05$ & $1.05-0.80$ & $0.80-0.60$ & 0.60 \\
\hline $\begin{array}{l}\text { Very } \\
\text { poor }\end{array}$ & $1.05-0.95$ & $0.95-0.75$ & $0.75-0.40$ & 0.40 \\
\hline
\end{tabular}

Table 1 indicates that the lower the drainage system quality and the greater the time in a year the pavement in saturation condition, the lower the drainage coefficient will be. The drainage coefficient will be used to estimate the magnitude of the structural number $(S N)$ of the pavement structure as follows:

$S N=a_{1} D_{1}+a_{2} D_{2} m_{2}+a_{3} D_{3} m_{3}$

in which: $a_{i}=$ layer coefficient; $D_{i}=$ layer thickness

\subsection{Quality of road pavement}

The quality assessment of the pavement is carried out using a combination of two functional condition parameters of the road, that is, International Roughness Index (IRI) and Surface Distress Index (SDI) [3]. The combination of the two parameters represents four functional conditions of the road (good, fair, slightly damage, and severely damage) as shown in Table 2 .

Table 2. Functional condition assessment of road pavement

\begin{tabular}{|c|c|c|c|c|}
\hline \multirow{2}{*}{$\begin{array}{c}\text { IRI } \\
(\mathrm{m} / \mathrm{km})\end{array}$} & \multicolumn{4}{|c|}{ SDI } \\
\cline { 2 - 5 } & $<50$ & $50-100$ & $100-150$ & $>150$ \\
\hline$<4$ & Good & Fair & Fair & $\begin{array}{c}\text { Slightly } \\
\text { damage }\end{array}$ \\
\hline $4-8$ & Fair & Fair & $\begin{array}{c}\text { Slightly } \\
\text { damage }\end{array}$ & $\begin{array}{c}\text { Slightly } \\
\text { damage }\end{array}$ \\
\hline $8-12$ & $\begin{array}{c}\text { Slightly } \\
\text { damage }\end{array}$ & $\begin{array}{c}\text { Slightly } \\
\text { damage }\end{array}$ & $\begin{array}{c}\text { Severely } \\
\text { damage }\end{array}$ & $\begin{array}{c}\text { Severely } \\
\text { damage }\end{array}$ \\
\hline$>12$ & $\begin{array}{c}\text { Severely } \\
\text { damage }\end{array}$ & $\begin{array}{c}\text { Severely } \\
\text { damage }\end{array}$ & $\begin{array}{c}\text { Severely } \\
\text { damage }\end{array}$ & $\begin{array}{c}\text { Severely } \\
\text { damage }\end{array}$ \\
\hline
\end{tabular}

\subsection{Pavement Serviceability Index (PSI)}

In this study, PSI is expressed as a function of pavement condition index (PCI) index and structure condition index (SCI) as [4] as shown in equation (3) - (5).

$$
\begin{aligned}
& P S I=f(P C I, S C I)<P S I_{T} \\
& P C I=(12.905-I R I) / 0.119 \\
& S C I=S N_{e f} / S N_{\text {min }}
\end{aligned}
$$

in which: $I R I=$ international roughness index, $P S I_{t}=$ terminal present serviceability index for design, $S N_{e f}=$ effective structural number, dan $S N_{\min }=$ minimum required structural number

Simamora dan Hatmoko [5] stated that $P S I_{t}$ values for non-toll national roads are in the range of $2.0-2.5$, while $S N_{\text {eff }}$ and $S N_{\text {min }}$ values are determined using equation (2) for existing condition and required structural conditions, respectively.

\section{Research method}

This study consists of several steps, as follows.

a. Data collection from case study location, i.e. Kendal Timur road. This is a national road that connects two cities in Central Java province, Semarang and Kendal. The data collected includes: (i) road damage data (the types, dimension and severity level of damages; and road roughness); (ii) road material properties; (iii) rainfall and drainage system data; (iv) traffic volume and axle load of various trucks; and (iv) existing road design. Especially for road damage data, the data was collected per $100 \mathrm{~m}$ long.

b. Calculation of PCI and SDI values based on data in point a.

c. Calculation of PSI based on PCI and SDI values and determination of the conformity of PSI values against terminal or minimum PSI required $\left(P S I_{t}\right)$ 


\section{Results and discussion}

\subsection{Analysis of overload condition}

Overloaded truck data was collected from load measurement at 16 weighbridge station around Kendal Timur road within period 2012 - 2015. In 2015, overloaded truck data could only be obtained from 8 weighbridge stations due to the closure of 8 other stations. This overload analysis was conducted based on overloaded truck accumulation trends that grouped the trucks into four overloaded categories, i.e. overloading (OL) less than 5\%, 5-15\%, 15-25\% and greater than $25 \%$ of allowable weight amount (JBI) [6] (see Figure 1).

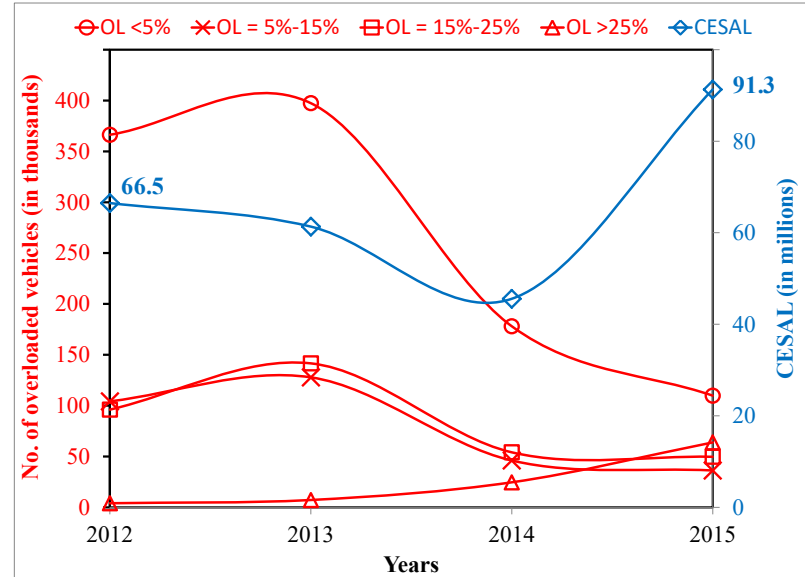

Fig. 1. Comparison between CESAL and overloaded category

Figure 1 also provides the number of axle loads of a heavy vehicle, collected from annual traffic count by P2JN (Design and Supervision of National Road) and expressed in cumulative equivalent standard axle load (CESAL), to provide a complete picture of the relationship between the number of equivalent standard axle load and the number of overloaded trucks.

In Figure 1, the number of trucks with excess loads (except overloaded trucks $>25 \%$ ) generally has a decreasing trend in the period of $2012-2015$, especially the number of overloaded truck in 2015. However, this is more due to only 8 weighbridge stations that provided a report of overload trucks in that year. On the other hand, the cumulative equivalent standard axis load (CESAL) of trucks through Kendal Timur road increased significantly to 91.3 million ESALs (or $50 \%$ higher than that in 2012, i.e. 66.5 million ESALs).

Using only a half (or 8 stations) of weighing bridges in operation and the increased number of truck axle loads, it can be estimated that the number of overloaded trucks will increase sharply, with patterns that resembling previous three-year pattern of trucks with overload less than $5 \%$, overload between $15 \%$ - $25 \%$, overload between 5\%-15\% and overload more than $25 \%$.

\subsection{Analysis of road damage}

As described in section 2.3, road damage represents the level of quality of a road that can be expressed in two parameters, namely the surface distress index (SDI) and road roughness (in terms of IRI). Although SDI and IRI both represent the quality of a road, but conceptually, the two parameters state two different things.

SDI is a composite parameter that represents the dimensions and severity of three most dominant types of road damage, namely cracks, potholes and rutting, while IRI expressed the unevenness of the road surface as a result of road damage. The unevenness calculated in IRI can be caused by one or a combination of 19 road damages, as said by Shahin [7]. Because of the difference of measurement method of the two parameters, both IRI and SDI become complementary parameters to be able to know functional condition of a road segment, as depicted in Table 2.

In this study, Kendal Timur road of approximately $2.3 \mathrm{~km}$-long (Km. $25+600$ to $27+823$ ) can be divided into 23 segments with a length per segment equals to 100 $\mathrm{m}$. For each segment, SDI and IRI data were plotted so that the illustration, as shown in Figure 2, could be obtained. Figure 2 represents the variation of SDI and IRI values for each segment of the road within 4 consecutive years (2012 to 2015). In that figure, different dot colour in Figure 2 is referring to the colour of the functional conditions in Table 2 .

From Figure 2, it can be highlighted the following:

a. The change of SDI value in year 2012 and 2013 indicated that there were road damages, in the form of potholes and ruts, especially at Km. $26+700$ to $27+700$. In general, overload is the dominant factor caused the damages, while poor drainage will play a role in exacerbating such damage. This shows up as high values of SDI in year 2013 and 2014. The occurrence of these two damages does not affect significantly on the change of IRI in year 2012 and 2013. It could be caused by the position of the potholes did not at the location of the tyre imprint where IRI device usually measures the roughness of the road surface;

b. In 2014, a repair of damaged roads in terms of potholes and ruts was conducted, by means of patching (except at $\mathrm{Km} 27+500$ to $27+700$ ). This patching caused a slight increase in the value of IRI.

c. In 2015 , a repair of damaged roads at Km. $27+500$ to $27+700$ has been conducted and causing IRI value in the segments to decrease. At the same time, there was road damage at $\mathrm{Km} .25+500$ to $26+300$ so that IRI value increases in this segment.

d. The increasing value of SDI in year 2013 and 2015 was caused by high traffic loads in both years, as shown in Figure 2.

e. The fluctuation of SDI and IRI values occurs repeatedly, and in different segments. 

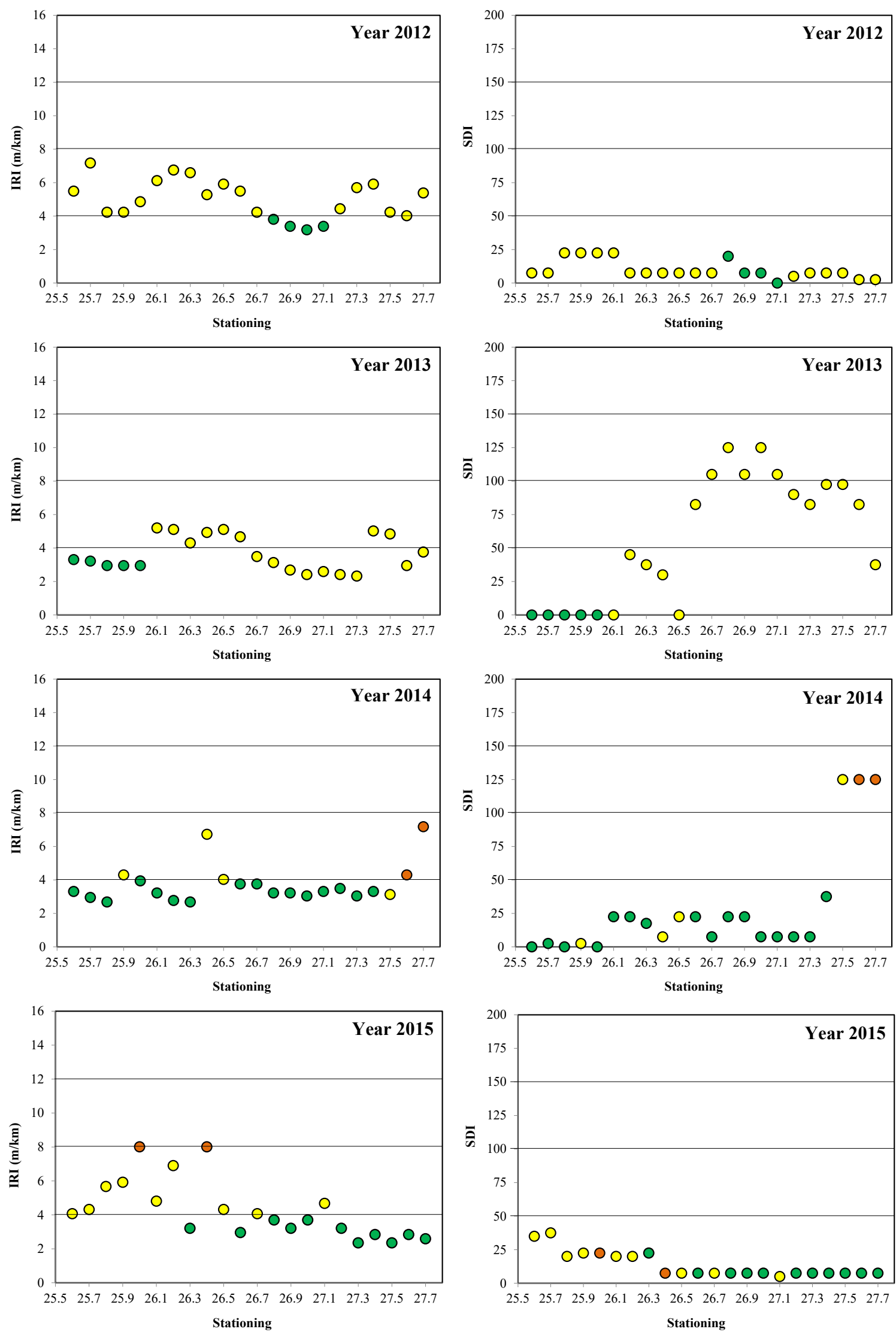

Fig.2. Functional condition of evaluated road segments in different years 


\subsection{Analysis of drainage condition}

Rainfall data was collected from Ketapang rain station around Kendal Timur Road, as shown in Table 3. From Table 3 and using a 5-year rainfall period, the rainfall intensity and flood rate could be calculated as follows: $I$ $=67.84 \mathrm{~mm}, Q_{t}=6.63 \mathrm{~m}^{3} / \mathrm{s}$ (for 1-hour raining period), $I=42.74 \mathrm{~mm}, Q_{t}=4.18 \mathrm{~m}^{3} / \mathrm{s}$ (for 2-hour raining period), respectively.

The drainage channels on both sides of Kendal Timur road have 2 different shapes, trapezium and rectangle, which have a capacity of $Q=5.24 \mathrm{~m}^{3} / \mathrm{s}$ and $0.51 \mathrm{~m}^{3} / \mathrm{s}$, respectively.

Table 3. Daily average maximum rainfall between 2006-2014

\begin{tabular}{|c|c|c|}
\hline Year & Date & $\begin{array}{c}\text { Daily average maximum } \\
\text { rainfall }(\mathrm{mm})\end{array}$ \\
\hline 2006 & 27 Jan 2006 & 172 \\
\hline 2007 & 06 Apr 2007 & 84 \\
\hline 2008 & 19 Dec 2008 & 51 \\
\hline 2009 & 09 Jun 2009 & 65 \\
\hline 2010 & 09 Jun 2010 & 110 \\
\hline 2011 & 06 Feb 2011 & 600 \\
\hline 2012 & 24 Nov 2012 & 91 \\
\hline 2013 & 17 Jun 2013 & 120 \\
\hline 2014 & 23 Jan 2014 & 145 \\
\hline
\end{tabular}

If the capacity of these two drainage channels is compared with the flood discharge, either for 1-hour or 2- hour raining time, it can be concluded that in general the existing drainage cannot accommodate rain-water $(Q$ $\left.<Q_{t}\right)$.

This indicates that there is a tendency that Kendal Timur road is always submerged when it rains. Beside the lack of drainage capacity, the occurrence of puddles was also contributed by the fact that drainage channels were often clogged by soil or waste (see Figure 3).

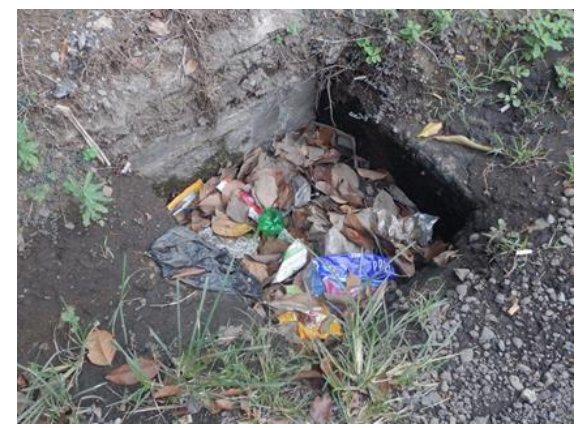

Fig. 3. Condition of drainage channel inlet filled with garbage

\subsection{Analysis of functional and structural failure}

This analysis aims to evaluate the condition of the road whether in the category of failed, critical or un-failed. A failure of a road pavement could be based on two conditions: functional and structural. Functional condition of a road can be assessed using PCI parameter, while the structural one can be evaluated using SCI parameter.

The value of $P C I$ could be determined using equation (4) and IRI data from Figure 2. On the other hand, to calculate the value of $S C I$, two components of $S C I$, i.e. $S N_{e f}$ dan $S N_{m i n}$, need to be determined using equation (2).

The value $D_{i}$ in $S N_{e f}$ dan $S N_{\text {min }}$ equations were obtained from design data, in which the thicknesses of $D_{1}, D_{2}$ dan $D_{3}$ equals to $5.12 \mathrm{in}$., $4.72 \mathrm{in}$. and $9.84 \mathrm{in}$., respectively. The value $a_{i}$ in $S N_{\min }$ equation was maximum value for each layer, i.e. $0.44,0.44$ and 0.11 , respectively, for materials of surface, base and subbase layers $\left(a_{1}, a_{2}\right.$ and $\left.a_{3}\right)$.

The material quality value $a_{i}$ for $S N_{\text {eff }}$ equation was obtained by means of visual condition survey per $100 \mathrm{~m}$ long of road segment to detect the presence of road damage: alligator cracking, transverse cracking and pumping. The result of the survey showed that alligator cracking with low severity level and area less than $10 \%$ dominated the damage of surface layer on several segments, while pumping damage was not found on base and subbase layers. Therefore, the selected $a_{i}$ for all layers were as follows [2]: $0.35-0.40,0.25-0.35$ and $0.10-0.14$ for $a_{1}, a_{2}$ and $a_{3}$, respectively.

The values of $m_{2}$ and $m_{3}$ in equation (2) were determined using the following equation:

$P=\left(T_{j} * T_{h} / 8760\right) *(1-C) * 100$

in which: $P=$ Percent of time pavement structure is exposed to moisture levels approaching saturation; $T_{j}=$ average rainfall in a day (hour); $T_{h}=$ average number of rainy days per year (day); $C=$ flow coefficient.

According to Ketapang weather station, the average rainfall in a day $\left(T_{j}\right)$ is 3 hours. To determine average number of rainy days per year, a data set of rainy days for period of year 2006 - 2014 was collected, it resulted $T_{h}$ equals to $70.89 \sim 71$ days. In addition, the flow coefficient $(C)$ equals to 0.7 based on Directorate General of Highway drainage design guide [8].

Using the values of $T j, T h$ and $C$ above, $P$ can be calculated, that is, equals to $0.73 \%$. The values of $m_{2}$ and $m_{3}$ then could be determined using Table 1. The observation of Kendal Timur road during rainy season indicated that water will completely remove after 1 day. According to AASHTO 1993 [2], the drainage quality as described above is in good category. Furthermore, based on $\mathrm{P}$ value and drainage quality, it could be determined that the values of $m_{2}$ and $m_{3}$ equal to 1.35 [2].

Using the values $a_{i}, D_{i}$ and $m_{i}$ above, $S N_{e f}, S N_{\min }$ and SCI (or rasio $S N_{e f}$ to $S N_{\text {min }}$ ) of Kendal Timur road can be calculated. The next step was to determine PSI as function of PCI and SCI (see equation (3)). Simamora [9] defined the equation (3) as follows.

$P S I=\alpha_{1} *[2+3 *(P C I-10) / 3]+\alpha_{2} *[\mathrm{SCI} * 2]$

in which: $\alpha_{1}$ and $\alpha_{2}=$ weight age factor for road functional and structural conditions, respectively. Both factors are determined using analytical hierarchy process 
(AHP) method based on experts' judgements in assessing the failure condition of pavement structures under different conditions. According to the experts' judgment, the value of $\alpha_{1}$ and $\alpha_{2}$ was set to 0.3 and 0.7 .

Table 3 shows the values of PCI, SCI and PSI that calculated using equations (4), (5) and (7). Condition status in Table 3 compares the measured PSI and terminal PSI (or $P S I_{t}$ ) and produces 3 pavement status, i.e. failed, critical and not-failed for $P S I<P S I_{t}, P S I=$ $P S I_{t}$ and $P S I>P S I_{t}$, respectively. The value of $P S I_{t}$ equals to 2.5 due to Jalan Kendal Timur is an arterial (non-toll) road [10].

Table 3. Condition status of pavement structure

\begin{tabular}{|c|c|c|c|c|c|}
\hline $\begin{array}{l}\text { Early } \\
\text { Km. }\end{array}$ & PCI & SCI & PSI & $\begin{array}{c}\text { Condition } \\
\text { status }\end{array}$ & $\begin{array}{c}\text { Pavement } \\
\text { status }\end{array}$ \\
\hline $25+600$ & 74.24 & 0.81 & 2.4 & $\mathrm{PSI}<\mathrm{PSI}_{\mathrm{t}}$ & Failed \\
\hline $25+700$ & 66.01 & 0.81 & 2.3 & $\mathrm{PSI}<\mathrm{PSI}_{\mathrm{t}}$ & Failed \\
\hline $25+800$ & 58.67 & 0.81 & 2.2 & $\mathrm{PSI}<\mathrm{PSI}_{\mathrm{t}}$ & Failed \\
\hline $25+900$ & 30.80 & 0.81 & 1.9 & $\mathrm{PSI}<\mathrm{PSI}_{\mathrm{t}}$ & Failed \\
\hline $26+000$ & 56.68 & 0.81 & 2.2 & $\mathrm{PSI}<\mathrm{PSI}_{\mathrm{t}}$ & Failed \\
\hline $26+100$ & 60.80 & 0.94 & 2.4 & $\mathrm{PSI}<\mathrm{PSI}_{\mathrm{t}}$ & Failed \\
\hline $26+200$ & 52.56 & 0.81 & 2.2 & $\mathrm{PSI}<\mathrm{PSI}_{t}$ & Failed \\
\hline $26+300$ & 67.02 & 0.94 & 2.5 & $\mathrm{PSI}=\mathrm{PSI}_{\mathrm{t}}$ & Critical \\
\hline $26+400$ & 40.13 & 0.94 & 2.2 & $\mathrm{PSI}<\mathrm{PSI}_{\mathrm{t}}$ & Failed \\
\hline $26+500$ & 59.79 & 0.94 & 2.4 & $\mathrm{PSI}<\mathrm{PSI}_{\mathrm{t}}$ & Failed \\
\hline $26+600$ & 84.58 & 0.94 & 2.7 & $\mathrm{PSI}>\mathrm{PSI}_{\mathrm{t}}$ & Not-failed \\
\hline $26+700$ & 67.02 & 0.81 & 2.3 & $\mathrm{PSI}<\mathrm{PSI}_{\mathrm{t}}$ & Failed \\
\hline $26+800$ & 39.12 & 0.81 & 2.0 & PSI $<\mathrm{PSI}_{t}$ & Failed \\
\hline $26+900$ & 67.02 & 0.81 & 2.3 & $\mathrm{PSI}<\mathrm{PSI}_{\mathrm{t}}$ & Failed \\
\hline $27+000$ & 8.11 & 0.81 & 1.7 & $\mathrm{PSI}<\mathrm{PSI}_{\mathrm{t}}$ & Failed \\
\hline $27+100$ & 39.12 & 0.81 & 2.0 & $\mathrm{PSI}<\mathrm{PSI}_{t}$ & Failed \\
\hline $27+200$ & 75.25 & 0.81 & 2.4 & $\mathrm{PSI}<\mathrm{PSI}_{\mathrm{t}}$ & Failed \\
\hline $27+300$ & 87.70 & 0.94 & 2.7 & $\mathrm{PSI}>\mathrm{PSI}_{t}$ & Not-failed \\
\hline $27+400$ & 83.57 & 0.81 & 2.5 & $\mathrm{PSI}=\mathrm{PSI}_{\mathrm{t}}$ & Critical \\
\hline $27+500$ & 87.69 & 0.94 & 2.7 & $\mathrm{PSI}>\mathrm{PSI}_{t}$ & Not-failed \\
\hline $27+600$ & 84.58 & 0.94 & 2.7 & $\mathrm{PSI}>\mathrm{PSI}_{\mathrm{t}}$ & Not-failed \\
\hline
\end{tabular}

Remarks: IRI data as in 2015

According to Table 3, there are 17 segments (71\%), 2 segments (10\%) and 4 segments (19\%) categorized as segments with failed, critical, and non-failed conditions. The main factor of the low PSI value that makes a segment categorized as failed is high IRI value (as a component of PCI). The high value of IRI can be contributed by road damages such as potholes or ruts, as a result of excessive load and submerged pavement structure. On the other hand, SCI values are generally less varied because of an assumption that the material quality is almost similar for the entire road segment.

\section{Conclusions}

This paper presented some causal factors of road damage, and how these factors can be formulated to determine the contribution of each factor to the occurrence of damage of road infrastructure. To obtain a comprehensive research result, Kendal Timur road was selected as the location of case study.

The results of this study show that un-functional drainage channels, uncontrolled overload due to the closing of weighbridge stations around the road, and also low quality of road maintenance work altogether are the factors that cause road damage.

The road roughness parameter (expressed as IRI) in the PCI function contributes significantly to the pavement serviceability index (PSI), while SCI parameters are not sensitive to PSI value. Based on the assessment of both PCI and SCI parameters of the road segment being the case study site, it can be determined that $71 \%, 10 \%$ and $19 \%$ of the road were in failed, critical and not-failed conditions, respectively.

The funding of this research was fully supported by Diponegoro University through Development and Implementation Research (RPP) Grant Scheme (Ref. 042.01.2.400898/2016)

\section{References}

1. B.H. Setiadji, S.P.R. Wardani. Evaluation of Wear of Surface Layer Due to the Influence of Traffic Loading and Weather (unpublished) (2010)

2. AASHTO. AASHTO Guide for Design of Pavement Structures (1993)

3. Directorate General of Highway. Road Condition Survey Guidelines No. SMD-03/RCS (2011)

4. G.D. Prabowo. V.D. Rahmawati. L. Djakfar. A. Wicaksono. Relationship between PCI and IRI (Case studi: Provincial roads at Mojokerto). (Department of Civil Engineering, Brawijaya University, 2013). [in Indonesian]

5. M. Simamora. J.U.D. Hatmoko. Determining a Threshold of Damaged Road Categorized to Fail of Service in Accordance with Road User Satisfaction. Int. J. Eng. Res. \& Tech., 2 (2013)

6. Government of Central Java Province. Control of Road Freight Transportation (2012). [in Indonesian]

7. M.Y. Shahin. Pavement Management for Airports, Roads, and Parking Lots, $2^{\text {nd }}$ Edition (2005)

8. Directorate General of Highway. Road Surface Drainage Design Guidelines (1990) [in Indonesian]

9. M. Simamora. Characteristic of failed-category damaged road on National Road in Indonesia (2015) [in Indonesian]

10. H. C. Hardiyatmo Pavement design and land investigation (2015) [in Indonesian] 